\title{
Adaptive behaviour of fishers to external perturbations: simulation of the Tasmanian rock lobster fishery
}

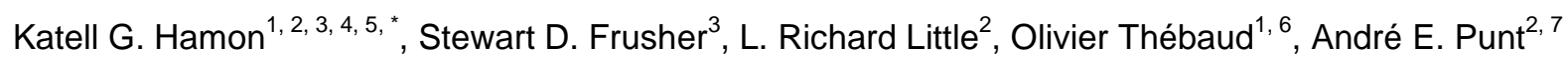 \\ ${ }^{1}$ Département d'économie maritime, UMR AMURE, IFREMER, Plouzané, France \\ ${ }^{2}$ CSIRO Wealth from Oceans National Research Flagship, CSIRO Marine and Atmospheric Research, Hobart, \\ TAS, Australia \\ ${ }^{3}$ Institute for Marine and Antarctic Studies-Fisheries, Aquaculture and Coasts, University of Tasmania, Hobart, \\ TAS, Australia \\ ${ }^{4}$ Université européenne de Bretagne, Université de Brest, UMR AMURE, IUEM, 12 rue de Kergoat, CS 93837, \\ 29238, Brest Cedex 3, France \\ ${ }_{5}$ Aquatic Resources, LEI Wageningen UR, 2502 LS, The Hague, The Netherlands \\ 6 CSIRO Wealth from Oceans National Research Flagship, CSIRO Marine and Atmospheric Research, \\ EcoSciences Precinct, Brisbane, Australia \\ ${ }^{7}$ School of Aquatic and Fishery Sciences, University of Washington, Seattle, WA, 98195-5020, USA
}

*: Corresponding author : Katell G. Hamon, email address : kg.hamon@gmail.com

\begin{abstract}
:
The rock lobster, Jasus edwardsii, lies on a global "hotspot" for climate change in the southeastern Australian state of Tasmania. The short-term effects of climate change are predicted to lead to an increasing exploitable biomass in the south and declining biomass in the north of the state. The future of the fishery is highly uncertain due to climate change, but also due to insecurities linked to the market conditions. The market for Tasmanian rock lobster is driven by the demand of a single market, China, which absorbs $75 \%$ of the catch. This study examines how fishers can adapt to external perturbations that affect the social and economic viability of the fleet and the ecological dynamics of the stock. Three fleet dynamic models of increasing complexity are used to investigate the effects of climate change and lobster price changes on the fishery. There could be local depletion leading to negative short-term profit for the fleet if it is static and the proportion of the total catch taken in each region of the fishery does not respond to climate-induced-changes. Better outcomes would occur if the fleet adapts dynamically to environmental conditions, and fishing effort follows stock abundance, which would counter-act the short-term effects of climate change. Only a model with explicit representation of economic drivers can fully capture the local economic and social impacts of large scale global perturbations.
\end{abstract}

Keywords: Tasmanian rock lobster ; Fleet dynamics ; Fishers behaviour ; Climate change ; 


\section{Introduction}

Climate change is presenting new challenges to scientists and managers of natural resources. In addition to the direct user-resource interactions, managers must progressively try to integrate the potential effects of climate-driven changes in the marine environment when defining management measures. Although uncertainty around the response of marine ecosystems to climate change is still high, expected impacts on marine communities and fisheries are increasingly studied and modeled (Perry et al. 2005; Cheung et al. 2009; Brown et al. 2010; Cheung et al. 2012; Heath et al. 2012). However, the responses of fishing fleets to climate perturbation are still often ignored (Haynie and Pfeiffer 2012). Both resource dynamics and the response of fishers must be considered to adequately support management measures (Fulton et al. 2011). Integrating these human dimensions explicitly into fisheries advice through the development of fleet dynamics models, coupled with biological models of fish populations, has been advocated by scientists for several decades (e.g. Hilborn 1985; Branch et al. 2006; Reeves et al. 2009; van Putten et al. 2012), and models have used a variety of approaches to capture the dynamics of fishery systems (such as the early fishery bio-economic models which included simulation and optimization, Charles 1995). Models exist to try to anticipate the behavioural response of fishers to changes in management measures (such as changing single-species quotas in a multispecies fishery - Poos et al. (2010); area closures - Soulie and Thebaud (2006); fishery closures - Vermard et al. (2008); spatial management Dowling et al. (2012)). However, these models are yet to be used for management advice. For example, the International Council for the Exploration of the Sea still provides advice to the European Commission solely based on ecological objectives and without integrating fleet responses in their assessment models.

While some of the drivers of fishing behaviour are directly linked to ecosystem characteristics, such as the abundance and spatial distribution of fish, economic factors such as fuel (Beare and Machiels 2012) or fish prices can lead to changes in fishing behaviour (van Putten et al. 2012). In this study, the effects of climate change and economic perturbations on a fishery are investigated using three models of fleet dynamics, coupled with a population dynamics model of the target resource. The three models present different degrees of complexity: (a) a model with a static fleet, (b) a model in which the fleet responds to biological drivers and (c) a model in which the fleet is driven by profit maximization. The models are used to predict the performance of the fishery in terms of ecological, economic, and social indicators. The extent to which predictions differ according to the behavioural model assumed is evaluated.

\section{The Tasmanian rock lobster fishery}

Tasmania, southeastern Australia (Fig. 1), is at the interface of the warm East Australian Current and cold southern ocean waters, and is one of the global climate "hotspots" where the signs of climate change are likely to be observed earlier than elsewhere (Johnson et al. 2011). Early signs of climate change are expected to be seen fairly rapidly in the southern rock lobster, Jasus edwardsii, fishery where growth and larval settlement are affected by currents and water temperature (Gardner et al. 2006; Linnane et al. 2010). The rock lobster fishery is the second most important wild fishery in Tasmania in terms of value, with an estimated value at first sale of around AUD $\$ 70$ million'. In addition, it is the top fishery in terms of employment, and is estimated to employ 760 people in fishing and processing (Pecl et al. 2009). Recreational fishing for rock lobster is also 
very important in Tasmania, with about 20,000 recreational licenses issued during the 2006/07 season (Lyle 2008). A Total Allowable Catch (TAC), allocated through individual transferable quotas (ITQs), was introduced into the commercial sector of this fishery in 1998, following concerns for the sustainability of the resource (Ford 2001). Following introduction of the TAC, catch rates have increased, the overall economic performance of the fishery has improved, and the stock has rebuilt (Hamon et al. 2009). Multiple factors have contributed to the recovery of the fishery, including several years of good recruitment combined with setting the TAC at a sustainable level. However, catch rates have recently been declining because of poor recruitment since 2008 (Gardner and Ziegler, 2010, Linnane et al., 2010), leading to a new management plan which includes cuts to the TAC (Anon 2010b). Climate change has been identified as a possible cause of the decline in recruitment, but the long term effects of climate change and the future of the fishery are uncertain (Pecl et al., 2009).

In addition to environmental pressures, the Tasmanian rock lobster fishery is also subject to economic risks. Most Tasmanian rock lobster is exported live to the Peoples Republic of China (henceforth "China"), and the industry relies entirely on this sole customer, making it very sensitive to the Chinese market (Bradshaw 2004). Fishers are aware of the risks associated with depending on a single market since the severe acute respiratory syndrome (SARS) outbreak in Asia in 2003, which caused the lobster price to suddenly drop in Tasmania, only to recover months later. However, China has been the fishery's best buyer, and Tasmanian processors persist on mainly working with this market (fisher, pers. comm.). The future of this fishery is therefore highly insecure with climate change reducing productivity, combined with economic uncertainty. This study investigates how the fishery could be impacted over the next 10 years by these factors.

\section{Model and data}

A bio-economic model was developed to explore the potential impacts of climate change on the sustainability of the fishery by capturing the main biological features of the southern rock lobster (Jasus edwardsii) population, as well as different levels of complexity in representing fleet responses to change. The model consisted of population dynamics and fleet dynamics modules developed for southern rock lobster fisheries off southern Australia (Punt and Kennedy 1997; Punt et al. 1997; Hobday and Punt 2001; Punt et al. 2006; Hobday and Punt 2009). This model is used to estimate current stock status and to project the stock into the future under a range of scenarios (Gardner and Ziegler 2010). It is spatially-explicit at a time scale of less than a year, with ecological processes and fishing activities modifying the lobster stock in each fishing area during each timestep. The dynamics of the fishery, and its impacts on the rock lobster stock, are captured using fleet dynamics modules integrated with the population dynamics module to project the stock forward. The pre-existing fleet dynamics model is used in two forms in the current study: one form assumes a constant spatial and temporal distribution of the catch, and the other allows the fleet to follow the exploitable biomass of the stock. The third fleet dynamics model is an agentbased model of fishing allocation and quota trading.

\subsection{Dynamics of the Tasmanian rock lobster population}

The population dynamics of Tasmanian rock lobster are modelled using timesteps of one to three months, and the model captures the size-structure of the 
stock (rock lobsters can not be aged). Three-month time-steps are used in the Austral winter because fewer data are available for this season. Although the Tasmanian rock lobster stock is managed as a single stock, the population dynamics model is parameterised separately in 11 assessment areas (Fig.1) inter alia because of the low rates of movement of rock lobsters after settlement. In the model, the population size-structure in each of the 11 fishing areas is modified during each time-step due to fishing and natural mortality; other biological processes including movement of lobsters between areas, growth and settlement, only occur during specific times of the year.

The natural mortality rate was estimated using tag-recapture data (Punt and Kennedy, 1997). It is set to $0.1 \mathrm{yr}^{-1}$ for all sizes, and is assumed to occur uniformly across the year. The fishing mortality for each area and time-step depends on the spatial and temporal allocation of recreational, commercial and illegal catches. The recreational catch is set at 150 tons per year (Lyle 2008). The spatial and seasonal distribution of the recreational catch is assumed constant. The commercial catch is based on user-specified annual TACs. The spatial distribution of the commercial catch in each time-step and area is determined using a fleet dynamics model (see the section on fleet dynamic models, below). Given the lack of information on illegal fishing, it is assumed that the illegal catch in each area and time-step is (an arbitrary) $2 \%$ of the commercial catch. There is no information on who practices illegal fishing and so no revenue from illegal activities nor changes in illegal fishing behaviour are considered in the analyses, i.e. illegal catches simply reduce the population dynamics in each area.

Recreational, commercial and illegal catches are distributed over sexes and sizes of rock lobster. Size-selectivity is represented by a sex-specific truncated logistic function to account for the minimum legal size $(105 \mathrm{~mm}$ and $110 \mathrm{~mm}$ for female and male, Punt and Kennedy 1997). A vulnerability coefficient is used to capture the relative availability of female compared to male lobsters, due to females being protected during reproduction. Females can not be retained from May to October (Anon 2006), so their vulnerability is set to zero during these months. In addition, females carrying eggs before May are also protected, and a vulnerability of 0.5 is assumed during April. Catchability coefficients represent the link between catch rates and local abundance. Constant from year to year, these parameters are estimated when the population dynamics model is fitted to the available data (Gardner and Ziegler 2010; Ziegler et al. 2003).

Migration of rock lobsters between fishing areas is limited. Rock lobsters exhibit high site-fidelity after settlement and no long-distance movement has been detected for Tasmanian rock lobsters (Gardner et al. 2003). Only minor inshoreoffshore movements have been identified from tag-recapture data so two-way migration between areas 6-9, 7-10 and 8-11 estimated from the tagging data is included in the model.

No stock-settlement relationship is defined for the Tasmanian rock lobster stock (Linnane et al. 2010). The stochastic settlement of juvenile lobsters in each area is estimated as the combination of an average settlement and an annual deviation. Growth of lobsters is modelled using transition matrices (Punt et al. 1997; McGarvey and Feenstra 2001). Gardner et al. (2006) showed that the growth rate of Jasus edwardsii around Tasmania increased in a south-north gradient. Area-specific transition matrices are used to capture this variation in growth rates. 


\subsection{Effects of climate change on the dynamics of the stock}

Environmental perturbations have recently been argued to have led to lower recruitment in southern rock lobster (Linnane et al., 2010). Although the exact causes of reduced recruitment are unclear, the change in regional currents induced by global climate change is the probable cause (Pecl et al., 2009). Climate change (manifested by increased water temperature) is likely to affect the settlement of juveniles negatively and the growth rates of settled lobsters positively. Temperature-dependent growth rates and settlement were implemented in the model with future temperatures estimated monthly for each area based on a mid-range emission scenario from the Intergovernmental Panel on Climate Change (IPCC scenario A1B), using OzClim for Oceans (Pecl et al., 2009). Since growth rates increase with water temperature (Gardner et al., 2006); warmer waters in the south of Tasmania are expected to lead to increased growth rates of rock lobster in the colder southern areas, but it is uncertain whether growth in the north of Tasmania will be impacted to the same extent as that in the south. Future growth per area, $G_{a, y}$ (area $a$, year $y$ ), depends on the temperature $T_{a, y}$ in area a for year $y$ using the warm area (area 5; Fig. 1) as a reference (equation 1 and 2 from Pecl et al. 2009).

Where

$$
G_{a, y}=\alpha_{a, y} G_{a, 2000}+\left(1-\alpha_{a, y}\right) G_{5,2000}
$$

$$
\alpha_{a, y}=\max \left(0, \min \left(1,1-\frac{T_{a, y}-T_{a, 2000}}{T_{a, 2000}-T_{5,2000}}\right)\right)
$$

Monitoring of lobster larvae has shown a long-term decrease in recruitment. The oceanographic processes leading to higher water temperatures are believed to lead to lower lobster recruitment (Linnane et al. 2010). Future recruitment $R_{a, y}$ in area $a$ and year $y$ can be modelled as an exponential function of temperature (equation 3 from Pecl et al. 2009).

$$
R_{a, y}=\tilde{R}_{a} \cdot e^{\lambda\left(T_{a, y}-15^{\circ} C\right)} \cdot e^{\varepsilon_{a, y}-\left(\sigma_{a}\right)^{2} / 2} \quad \varepsilon_{a, y} \square N\left(0,\left(\sigma_{a}\right)^{2}\right)
$$

where $\tilde{R}_{a}$ is the recruitment in area a at $15^{\circ} \mathrm{C}, \lambda$ is the rate at which recruitment changes with temperature and $\sigma_{a}$ the standard deviation of recruitment in area $a$.

\subsection{Fleet dynamics models}

The fleet dynamics components of the model define the spatial and temporal distribution of fishing effort and therefore lobster catch. The three models used in this study are: (a) a model with a constant spatial and seasonal catch distribution (FD0), (b) a model linking catch distribution and local biomass linearly (FD1, used in Pecl et al. 2009), and (c) a model explicitly representing quota owners decisions about fishing and quota leasing (FD2, Hamon 2011).

The general equation governing the allocation of the TACC to area and time-step for models FD0 and FD1 is:

$$
H_{a, p, y}=\lambda_{p, y} P_{a, p, y} T A C C_{y}
$$


where $H_{a, p, y}$ is the catch from area a during time-step $p$ of year $y, \lambda_{p, y}$ is the proportion of the TACC for year $y$ taken during time-step $p$, and $P_{a, p, y}$ is the proportion of the catch during time-step $p$ of year $y$, which is taken in area $a$.

The proportion of the TACC taken in each time-step is assumed to be independent of time and area for models FD0 and FD1 (i.e. $\lambda_{p, y}=\lambda_{p}$ ). In model FD0, the proportion of landings per area per time-step, $P_{a, p, y}$, is fixed at historical levels (i.e. $P_{a, p, y}=P_{a, p}$ ). In model FD1, the spatial allocation of the landings is calculated assuming that the fishers are driven by perfect knowledge of the levels of exploitable biomass in area $a$ at the start of period $p$ of year $y$, $B_{a, p, y}^{\text {exploit }}$, although inertia is also captured through the constant, $\delta_{a, p}$ (equation 5).

$$
P_{a, p, y}=\frac{\exp \left[\delta_{a, p}+\beta_{a, p} B_{a, p, y}^{\text {exploit }}\right]}{\sum_{a^{\prime} \in A} \exp \left[\delta_{a^{\prime}, p}+\beta_{a^{\prime}, p} B_{a^{\prime}, p, y}^{\text {exploit }}\right]}
$$

The fishing effort for each time-step and area, $E_{a, p, y}$, used to calculate fishing costs, is derived from the catch and the exploitable biomass $B_{a, p, y}^{\text {exploit }}$ assuming that catchability, $q_{a, p}$, depends on area and time-step but is independent of year (equation 7):

$$
E_{a, p, y}=\frac{H_{a, p, y}}{q_{a, p} \cdot B_{a, p, y}^{\text {exploit }}}
$$

FDO is simple, but relies on the strong assumptions that the fleet remains unchanged and the fishers behave the same over time. Model FD1 is used to project the future of the fishery in the annual stock assessments. It implies that the fishery will respond to perturbations affecting the stock, but not to changes in the economic conditions under which the fleet operates, as it does not depend on the costs and earnings associated with fishing.

Model FD2 is an agent-based model that integrates the short-term decision processes of quota owners as to whether, when and where to fish, as well as whether to lease (in or out) quota. Choices of fishing effort allocation and quota trading are based on expected short-run marginal profit (table 1) for each vessel and month, which depends on individual vessel fishing costs and revenues (Hamon 2011). Vessel-specific costs of fishing in an area depend on the size of the vessel and its home port. Revenues from fishing depend on the catch composition in terms of size and colour, and on the beach prices of each lobster category. with small plate-size red lobsters fetching the highest prices (Chandrapavan et al. 2009). Size and colour composition of catch are assumed to be area-dependent, with slower growth in the south and bright red lobsters typically found in shallow waters. Individual catch rates depend on area- and time-step, as well as vessel fishing efficiency. Individual fishing efficiency is defined as the historical deviation of the catch-rate of an individual vessel from the fishery average. For each month, quota owners decide stochastically to fish in the most profitable area or to lease their quota based on expected profits (chapter 4 Hamon 2011). Expected profits per month are updated based on "observed" catch-rates and lobster prices in the previous month and during the same month in the previous year. In addition to ecological perturbations detected 
through catch rates, economic changes (e.g. in fishing costs, in the demand and price by lobster category, and in the beach price seasonality) will also trigger responses from the fishery in model FD2.

\subsection{Data and model calibration}

The biological model is calibrated using spatially-explicit catch and effort data from the fishers' compulsory logbooks and tagging data (source: Department of primary industries, parks, water and environment, DPIWPE and IMAS-FAC). The initial status of the stock was taken as that estimated for 2006 in the 2010 assessment (Gardner and Ziegler 2010).

Economic data used include the short-term costs and prices. Such data are not collected routinely in the Tasmanian rock lobster fishery and consequently had to be extracted from various sources (table 2). Revenue depends on the price of lobsters determined by the colour and size categories. Variable costs include fishing costs (bait, ice, food for the crew, and fuel costs depending on fuel price and individual fuel usage), labour costs (crew and skipper wages, minimum level set at their opportunity cost of fishing), and gear and equipment maintenance costs. Unit costs are held constant in the simulations except for labour, for which a $4 \%$ annual increase is assumed (based on the trend observed the Australian Bureau of Statistics, http://www.abs.gov.au). Fishing costs depend on both the location and time of fishing, and on the fisher operating (to account for vessel size and port of origin). In models FD0 and FD1, the fleet is not explicitly described so cost differences that could relate to geographical origin (e.g. fuel prices) or vessel size are not modelled, and the estimated unit costs are only used to calculate economic performance indicators at fishery-level. Time-stepand area-specific costs are estimated per unit of effort to obtain comparable model outputs, multiplied by an annual trend factor.

Quota ownership and traded volumes are also recorded in the DPIPWE databases although the prices at which quota is leased are not recorded. Agents in model FD2 are defined as the quota owners at the beginning of the first quota season of the simulation period, March 2007 (quota seasons are from March to February of the following year). Quota owners were linked to a vessel through the DPIPWE licence and unloading databases. Overall, 292 businesses were identified, of which 216 owner-operators and 76 investors (quota owners without vessels). Agents in the model are allocated their quota shares as observed in 2007. Additional characteristics are used to describe owner-operator agents, including fishing efficiency, port of origin, and size of the vessel.

The TACs for 2007-2016 are set to decrease gradually from 1523t in 2007 and 2008 to 1200 t for 2012-2016 based on the actual TACs until 2009 and the proposed management plan since 2010 (Anon 2010b).

\subsection{Scenarios}

The Tasmanian rock lobster fishery is subject to many constraints over which stakeholders have no influence. Here, the effects of climate change on the fishery are investigated using two scenarios:

1. CC - Climate change effect: growth rate and recruitment are functions of sea temperature changes;

2. noCC- No effect of climate change. 
Scenarios related to future lobster prices are also investigated. The beach price of rock lobster varies seasonally and inter-annually in response to variation in the demand on the Chinese market (Hamon et al. 2009). Traditionally, the price is higher during winter, and decreases during the Austral summer (November to March, Hamon et al. 2009). However, the seasonal pattern is weaker since the 2008-2009 fishing season, because the summer decline in prices has been reduced, supposedly due to lower production of rock lobster coming from Western Australia representing $65 \%$ of Australian lobster production in 20062007`, \Anon, $2008 \# 1205\}$. The inter-annual trend and seasonal pattern of lobster price are separated using the Hodrick-Prescott filter (Hodrick and Prescott 1997, as used in Hamon et al. 2009) and two scenarios of seasonal patterns are investigated:

1. HistS: uses the historical seasonal pattern for beach prices (2005-2007) ;

2. NewS: uses the weaker seasonal pattern observed in recent years (20082010).

with two scenarios of annual trends:

1. IncP: increases prices at the same rate as the last eight months for which data were available (about \$2 per year)

2. ConP: uses a constant price at the level of the last available data (in April 2010).

Price differences between lobster size and colour categories are assumed to remain constant throughout the projection period.

Climate change effects are investigated for the scenario with increasing lobster price and the new seasonal pattern (CC-NewS-IncP and noCC-NewS-IncP). The effects of lobster price on the fishery are examined combining seasonal patterns and annual trends assuming climate change (CC-NewS-IncP, CC-HistS-IncP, CC-NewS-ConP, CC-HistS-ConP).

The three fleet dynamic models are used to assess the five scenarios over a 10year period (2007-2016). Monte Carlo simulations account for stochasticity in recruitment (all models) and in the decision process (FD2, table 1), using 50 iterations for each scenario. The same 50 time-series of annual recruitments are used for all analyses, and the same draws are used for discrete decisions in model FD2 for all scenarios to allow comparability among scenarios.

Several indicators are used to assess the future performance of the fishery for the various scenarios. The ecological status of the fishery is assessed through the exploitable biomass for each fishing area relative to the lowest regional level of exploitable biomass since the quota management system was introduced in 1998 (as in the 2009 assessment, Gardner and Ziegler 2010). Fishery revenue is calculated as the total value landed (sum of product of catch by month and colour-size category multiplied the beach price for that category and month). Given that only variable costs of fishing are considered, the fishery profit projected by the model is the annual short-term profit. The number of active fishing vessels is used as an indicator of social outcomes for the fishery in the agent-based model (FD2). This number is kept at its 2007 level in the other two models and is presented for comparison purposes. 


\section{Results}

\subsection{Effect of climate change on the stock}

The effects of climate change on the Tasmanian rock lobster stock vary among areas. With warmer conditions, the exploitable biomass is predicted to increase in the southern areas in the short-term through faster growth and to decrease in the north as reduced settlement affects the exploitable stock. The contrasting effects of climate change on biomass between the north and the south is observed in the simulation results (Fig. 2). Regardless of the fleet dynamics model used, the exploitable biomass is higher in the south under climate change compared to without climate change (the black lines for the CC-NewS-IncP scenario are above the grey lines for the noCC-NewS-IncP scenario). Conversely, exploitable biomass is lower in the north under climate change (the black lines for the CCNewS-IncP scenario are below the grey lines for the noCC-NewS-IncP scenario).

\subsection{Performances of models}

Model predictions of the distribution of catch and effort are compared to observations for the first three years under ITQ management (2007-2009) in Figs 3 and 4 . The three effort dynamics models capture the observations to varying degrees in the different areas (i.e. the black dots on Figs 3 and 4 compare differently to the model predictions in different areas). Model FD0 overestimates the amount of catch and effort in the north of Tasmania (areas 4 and 5) and in deep water in the west (area 9), whereas catch and effort are underestimated in the southern areas (areas 1 and 8). Model FD1 overestimates catch and effort in area 6, and underestimates catch and effort in area 7. In other areas, catch predictions are close to the observed values, although the estimated effort for the levels of catch observed is underestimated in area 1 and overestimated in area 8. Model FD2 tends to overestimate the amount of effort and catch off the west coast of Tasmania (areas 6 and 9), and tends to underestimate effort and catch in the northern areas (areas 4 and 5), effort on the east coast (areas 2 and 3) and in the southern areas (1 and 8 ). However, model FD2 correctly predicted the catch in areas 2 and 3 , and only slightly underestimated the catch in areas 1 and 8.

\subsection{Response of the fishing fleet}

\subsubsection{To climate change}

The fleet dynamics models differ in their predictions of the fleet's reaction to changes induced by climate change (CC-NewS-IncP, black lines in Fig. 4). Although the effect of climate change on the local biomass is consistent for the three fleet dynamics models (higher biomass in the south, lower in the north), the differences observed among the models arise from the different degrees to which the fleet adapts to a changing environment by modifying its fishing practices. Fleet dynamics models FD1 and FD2 predict more catch in the south of the state and less in the north if climate change impacts the stock, while fishing effort would increase in the north of the state and decrease in the south under model FDO given that the spatial allocation of the catch is constant under this model (Figs 3 and 4).

There is more difference between the local biomass for scenarios CC-NewS-IncP and noCC-NewS-IncP when the fleet does not adapt its fishing practices (FDO) compared to when this occurs (FD1 and FD2) (Fig. 2). The response of the fleet, 
modifying its fishing practices, thus reduces the effects of climate change on local biomass under models FD1 and FD2.

\subsubsection{To economic perturbations}

The catch distribution by area for the models FD0 and FD1 is not affected by price changes over time and seasonally because the fleet does not respond to economic stimuli in those models. Changes in the spatial distribution of catch and effort for model FD2 are also limited as price differences among market categories are assumed to remain constant over the projection period, so the relative attractiveness of one area compared to another in terms of catch composition does not change over time. However, the change in price seasonality influences catch seasonality. The proportion of lobsters caught during winter is expected to be higher with the historical seasonal pattern (scenarios CC-HistS-IncP and CC-HistS-ConP) than for the scenarios with lower marked price seasonality (CC-NewS-IncP and CC-NewS-ConP), owing to higher expected prices during winter.

The proportion of lobster caught during winter (May-September) remains stable over $2007-2016$ at around $23 \%$, if prices vary seasonally as they have done historically and there is a continuing upward trend in prices (scenario HistS-IncP). However, the proportion of the catch taken during winter decreases under the other scenarios. The differences in the proportion of the catch taken during winter between scenario CC-HistS-IncP and the other scenarios are not significant in 2007, while agents catch 5 to $7 \%$ more lobsters during winter 2016 in the HistSIncP scenario (i.e. assuming higher winter prices and that the annual trend in price continues) compared to all the other scenarios (table 3).

\subsection{Performance of the fishery under perturbations}

The environmental pressures applied to the fishery and the way the fleet responds to those perturbations affect the ecological, economic and social viability of the simulated fishery. The predicted ecological sustainability of the fishery is assessed through the local biomass relative to its lowest observed level in each area (Fig. 5). The increase in biomass under climate change in the southern areas attracts effort from northern areas (areas 4 and 5) resulting in area-specific biomass in the south (areas 1, 2, 8 and 11) in 2016 being closer to the lowest observed biomass for models with a dynamic fleet. In contrast, this effect is lower for the static model where the fleet can not re-distribute its effort (Fig. 5a). The redirection of effort from northern to southern areas under climate change releases pressure on the northern areas (areas 4 and 5), which results in the predicted biomass moving from below the lowest observed biomass (model FD0) to being above this for those areas (models FD1 and FD2) (Fig. 5a).

Changes in the economic viability of the fishery are determined by changes in either costs, revenue or both (Fig. 6). As expected given a pre-specified series of TACs, the total revenue from fishing shows little variability among models and among runs for a scenario (Fig. 6a). However, the fishing costs are considerably higher for a static fleet (Fig. 6b). The effort needed to take the historical proportion of the TAC in the northern areas, which exhibit declining trends in biomass, drives fishing costs to extreme values, potentially resulting in negative short-term profit for the fishery (negative error bars in Fig. 6c). Aggregated fishing costs predicted by model FD2 are expected to be considerably lower than those predicted by the other models, because only the most efficient agents remain active in the fishery, leasing quota from less profitable, less favourably located operators. FD2 may underestimate aggregate fishing costs, because it assumes 
perfect adjustment of operations to optimal levels and patterns of fishing, when a number of constraints may prevent such adjustment to occur in reality. As expected, the scenarios on beach price trends investigated in this study strongly affect the economic performance of the fishery which becomes less profitable if prices remain constant than if there is an annual increasing trend in lobster prices (Fig. 6c). However, the fishing effort distribution is not predicted to change with the different prices. The number of active vessels (and therefore direct employment in the fishery) is considered here as an indicator of the social impacts of the perturbations on the fishery. The size of the simulated fleet, when this is endogenous to the model (FD2), significantly decreases in the projections (Fig. 7). The extent to which this decrease occurs is directly related to the projected changes in profitability of the fishery (see profit Fig. 6c).

\section{Discussion}

This study examined the effect of external perturbations on a fishery system and how the likely change in fisher behaviour in response to climate change and economic perturbations may affect the bio-economic status of the fishery. The effects of climate change on the lobster stock are contrasted between the northern and southern areas. The growth rate of lobster has always been higher in the northern warmer waters (areas 4 and 5) than in the south where water is colder (Gardner et al. 2006). There, the reduction of settlement of larvae and recruitment of juvenile lobsters is already observed by fishers, resulting in an exploitable stock that is not renewed and composed principally of larger, lowvalued lobsters (lobsters over $2 \mathrm{~kg}$ can fetch up to AUD\$10/kg less than smaller lobsters). Conversely, the increase in growth rate has resulted in higher profitability from increased catch rates in southern areas as a higher proportion of the large undersized biomass attains legal size (Gardner and Ziegler 2010). The drop in predicted recruitment will eventually affect the southern areas, but the time-series is too short to detect this now.

Three fleet dynamics models were used to investigate potential consequences of these perturbations. The combined effects of climate change and a static fleet (FD0) led to predictions of local depletions in the north of Tasmania. This depletion was coupled with highly unrealistic levels of effort so that the proportion of the TAC caught in the northern areas could be maintained. This results in high fishing costs compromising the economic viability of the fleet. In addition, the between-run variability of predictions using the FD0 model directly reflects the variability in recruitment and in prices, and is consistently higher than the between-run variability from models with dynamic fleets (see exploitable biomass, Fig. 5 and economic indicators, Fig. 6). A static model predicts that there is a considerable risk that the commercial fishery would cease to exist by 2016 under the assumption that climate change will impact the stock as it is modelled in this study.

In contrast, models including a fleet response module (FD1 and FD2) predict a redirection of fishing effort towards the south of Tasmania where the biomass is predicted to increase with climate change and, when the fleet is driven by profit (FD2), away from the northern areas and large lobsters (high grading is not included in the model and all catch is assumed to be retained, even the lowervalued large lobsters). The catches under models FD1 and FD2 converge towards the end of the simulation period for most areas. The similarity between the spatial distribution of effort under models FD1 and FD2 is expected because climate change directly affects the biomass (which is a key driver of the FD1 
model) and subsequently catch rates (which drive effort allocation through marginal profit in model FD2). Only deepwater areas on the west coast show notable differences between models FD1 and FD2, with higher catches when effort dynamics are driven by profit, leading to lower biomass in these areas. The fleet is highly attracted to areas 6 and 9 under model FD2 due to relatively high expected catch rates (also observed in the fishery see Gardner and Ziegler, 2010). Real-life factors such as dangerous weather probably keep the fleet from fishing more in areas 6 . These factors are not captured in the calculation of profit, but are implicitly captured by model FD1 through its area-factors (equation 5). Such factors could be included in a refined behavioural model (as done in Smith 2002).

Changes in fishing behaviour under models FD1 and FD2 seem to attenuate the effect of the perturbations on the overall biological and economic status of the fishery. In particular, although the effect of uncertainty regarding input parameters should be further investigated using sensitivity analysis, it seems that the complex fleet dynamics model (FD2), including its stochastic elements, does not necessarily increase the uncertainty in results, because fishers adapt their behaviour to counteract the negative effects of external perturbations. This is important when studying the economics of a fishery, because variability in profits is usually a key driver of a firm's decisions about investment and production.

The dynamics of the fleet counteract the effects of climate change on biomass, resulting in the reduction in biomass being more evenly distributed among areas. This result may be important for managers, given that spatial management of the Tasmanian rock lobster fishery has been considered, but some operators prefer to be able to fish their quotas anywhere around Tasmania, rather than being constrained to particular areas. The simulation results seem to indicate that spatial management could be detrimental to the viability of the fishery in some areas (particularly in the north) given the impacts of climate change. Model comparison also shows that a simple fleet dynamics model integrating a catchrate effect in the spatial allocation of catch (FD1) will successfully predict the spatial redistribution of the fishing fleet to changes in the fish stock when calibrated over the right period. However, model FD1 does not account for economic factors in the choice of fishing seasons and areas. Changes in the seasonal pattern of the lobster price affect the seasonal distribution of effort (as observed after the introduction of quota in Hamon et al. 2009). The composition of the catch also plays an important role in the Tasmanian rock lobster fishery. Fishers have changed their fishing strategies to target more valuable size and colour categories of lobster since the introduction of ITQs (Hamon et al. 2009). The implications of this for predicting spatial and temporal fishing patterns can only be investigated using models that include fleet responses to economic drivers, such as model FD2. Climate change impacts also can lead to changes in the spatial distribution of fishing activity at regional scales (Charles 2009). The decrease in fleet size simulated in FD2 is not uniformly distributed around Tasmania. As expected, simulations show that the northern fleets are likely to be the most affected, being closer to the areas where the abundance of the most valuable lobsters will decrease first.

Taking into account economic drivers requires the collection of economic information which may not always be available. However, the same information is needed to calculate cost estimates for evaluating the outcomes of simpler models such as FD1. Moreover, additional hypotheses are required to calculate average costs per unit of effort for the fleet for the FD1 model (i.e., on the composition of the fleet and the fact that active fleet size remains constant). Ultimately, the economic assessment of the fishery-level outcomes is where disparities appear 
among the three fleet dynamics models. Although it predicts a reduced fishing fleet, the FD2 model leads to the most optimistic prognosis for the future of the fishery. FD1 predicts that the current fleet would still be profitable in 2016 (but less than FD2), while the FD0 model essentially predicts the end of rock lobster commercial fishing in Tasmania if the climate-change driven trends in recruitment and growth rates persist.

\section{Conclusion}

Climate change will certainly play a major role in defining the future of the Tasmanian rock lobster fishery. The findings of the current study confirm the prediction of Pecl et al. (2009) that the short-term effects of climate change, leading to an increase in biomass through faster growth in the south of the state, could lead to shift of fishing effort towards the south to harvest this increased biomass. The predictions are different in the north because the lack of recruitment will result in the decline of local biomass and lower fishing effort. As projections in this study only explore the fishery until 2016, the positive effect of higher growth rates outweigh the reduction in recruitment, and the overall performance of the fishery is still reasonably good at the end of the simulation period, but it is probable that longer projections would lead to a more pessimistic appraisal of the sustainability of the fishery if the poor recruitment persists.

The simulations carried out in this study show that fisheries assessment models which assume a static fleet (such as FD0) may in fact imply particularly strong assumptions regarding fishing effort and its allocation, which have major consequences on predictions of both the level and variability of key performance indicators at local and fishery levels. While in some cases (e.g. evaluation of very short term impacts of an environmental perturbation, or cases where fleet response is effectively constrained) such assumptions may be acceptable, it is likely that this will not be the case in most fisheries management contexts. In particular, given the time frames considered when examining the potential impacts of climate change on fisheries, it seems reasonable to expect that some fleet response will need to be included in the models used to examine these impacts, if the assessments are to be considered realistic. Assuming a dynamic response of the fishery allows an evaluation of the ecological impacts of perturbations, as well as of changes in the fishery, both in terms of reallocation of fishing effort (FD1 and FD2) and in terms of economic performance (FD2). The future of the fishery probably lies between the two dynamic models proposed here; FD2 as it is currently defined is likely to overstate the adaptation of the fleet to change, as it assumes perfect adjustment of operators to changed bioeconomic conditions, while FD1 predicts a greater inertia. Further research into the various drivers of fishing activity will allow improved models to be developed for this and other fisheries around the world \{Branch, 2006 \#144;Fulton, 2011 \#1211;Nøstbakken, 2011 \#1259\}. The development of such fleet dynamic models offers many advantages, including the ability to test a broader range of scenarios, and to include diverse performance metrics in the overall assessment of fisheries, including ecological, economic and social dimensions.

Fishers' behaviour follows simple profit maximizing rules in model FD2. This profit-maximising behaviour has important implications for the predicted spatial distribution of fishing effort, and the economic performance of the fleet. Other drivers could also be included that are known to influence the choice of effort allocation (see van Putten et al. 2012 for the factors incorporated in behavioural models of fishing fleets). Although the simulated fleet is probably adapting faster 
under model FD2 than in reality, this model is a useful approach to forecast the repercussions of external perturbation on the fishery after the reaction of the fleet is taken into account.

\section{Acknowledgments}

We are grateful to Ingrid van Putten and Caleb Gardner for the ex-vessel prices of lobster and costs data and to Klaas Hartmann for the biological data on the fishery. We would like to thank Natalie Dowling, Neil Klaer and two anonymous reviewers for their comments on a previous version of the manuscript. The first author was supported by a PhD scholarship co-funded by IFREMER and the joint CSIRO-UTAS Quantitative Marine Science program (QMS). The collaboration was financially supported by a cotutelle travel grant from the French Embassy and the French-Australian Scientific and Technological cooperation program (http://www.umr-amure.fr/pg fast.php).

\section{References}

Anon (2006) Fisheries (rock lobster) rules 2006. Tasmanian Parliament, Hobart Anon (2008) Australian Fisheries Statistics 2007. ABARE, Canberra

Anon (2010a) NPF RAG Assessment 2009/10. vol 2008/0824. Australian Fisheries Management Authority, Canberra

Anon (2010b) Rock Lobster Management Plan Review: Preliminary Proposals for New Management Measures for the Tasmanian Rock Lobster Fishery. Discussion Paper. Department of Primary Industries, Parks, Water and Environment - Wild Fisheries Branch, Hobart

Beare D, Machiels M (2012) Beam trawlermen take feet off gas in response to oil price hikes. ICES JOURNAL OF MARINE SCIENCE 69 (6):1064-1068. doi:10.1093/icesjms/fss057

Bradshaw M (2004) A combination of state and market through ITQs in the Tasmanian commercial rock lobster fishery: the tail wagging the dog? Fish Res 67 (2):99-109

Branch TA, Hilborn R, Haynie AC, Fay G, Flynn L, Griffiths J, Marshall KN, Randall JK, Scheuerell JM, Ward EJ, Young M (2006) Fleet dynamics and fishermen behavior: lessons for fisheries managers. Canadian Journal of Fisheries and Aquatic Sciences 63 (7):1647-1668

Brown CJ, Fulton EA, Hobday AJ, Matear RJ, Possingham HP, Bulman C, Christensen V, Forrest RE, Gehrke PC, Gribble NA, Griffiths SP, LozanoMontes H, Martin JM, Metcalf S, Okey TA, Watson R, Richardson AJ (2010) Effects of climate-driven primary production change on marine food webs: implications for fisheries and conservation. Global Change Biology 16 (4):1194-1212. doi:10.1111/j.1365-2486.2009.02046.x

Chandrapavan A, Gardner C, Linnane A, Hobday D (2009) Colour variation in the southern rock lobster Jasus edwardsii and its economic impact on the commercial industry. New Zealand Journal of Marine \& Freshwater Research 43 (1):537-545

Charles A (2009) The Interaction of Fisheries and Climate Change: Socioeconomic and Management Perspectives. ICES CM 2009/F:03. International Council for the Exploration of the Sea, Copenhagen

Charles AT (1995) FISHERY SCIENCE - THE STUDY OF FISHERY SYSTEMS. Aquatic Living Resources 8 (3):233-239. doi:10.1051/alr:1995023

Cheung WWL, Lam VWY, Sarmiento JL, Kearney K, Watson R, Pauly D (2009) Projecting global marine biodiversity impacts under climate change $\begin{array}{llll}\text { scenarios. Fish Fish } 10 & \text { (3):235-251. doi:10.1111/j.1467- }\end{array}$ 2979.2008.00315.x 
Cheung WWL, Pinnegar J, Merino G, Jones MC, Barange M (2012) Review of climate change impacts on marine fisheries in the UK and Ireland. Aquat Conserv-Mar Freshw Ecosyst 22 (3):368-388. doi:10.1002/aqc.2248

Dowling NA, Wilcox C, Mangel M, Pascoe S (2012) Assessing opportunity and relocation costs of marine protected areas using a behavioural model of longline fleet dynamics. Fish Fish 13 (2):139-157. doi:10.1111/j.14672979.2011.00422.x

Ford W (2001) Restructuring the Tasmanian rock-lobster fishery - the effect of two years of management under individual transferable quotas. Marine and Freshwater Research 52 (8):1641-1648

Fulton EA, Smith ADM, Smith DC, Van Putten IE (2011) Human behaviour: the key source of uncertainty in fisheries management. Fish Fish 12 (1):2-17. doi:10.1111/j.1467-2979.2010.00371.x

Gardner C, Frusher S, Barrett N, Haddon M, Buxton C (2006) Spatial variation in size at onset of maturity of female southern rock lobster Jasus edwardsii around Tasmania, Australia. Scientia Marina 70 (3):423-430

Gardner C, Frusher S, Haddon M, Buxton C (2003) Movements of the southern rock lobster Jasus edwardsii in Tasmania, Australia. Bulletin of Marine Science 73 (3):653-671

Gardner C, Van Putten El (2008) The economic feasibility of translocating rock lobsters to increase yield. Reviews In Fisheries Science 16 (1-3):154-163

Gardner C, Ziegler P (2010) Tasmanian rock lobster fishery 2008/2009. Tasmanian Aquaculture and Fisheries Institute, University of Tasmania, Hobart

Hamon KG (2011) Bio-economic analysis of the response of a fishery to changes in access regulation: the case of Individual Transferable Quotas in the Tasmanian rock lobster fishery. Ph.D thesis, University of Tasmania \& Université de Bretagne Occidentale, Hobart - Brest

Hamon KG, Thébaud O, Frusher S, Little LR (2009) A retrospective analysis of the effects of adopting individual transferable quotas in the Tasmanian red rock lobster, Jasus edwardsii, fishery. Aquatic Living Resources 22 (4):549-558

Haynie AC, Pfeiffer L (2012) Why economics matters for understanding the effects of climate change on fisheries. ICES Journal of Marine Science: Journal du Conseil. doi:10.1093/icesjms/fss021

Heath MR, Neat FC, Pinnegar JK, Reid DG, Sims DW, Wright PJ (2012) Review of climate change impacts on marine fish and shellfish around the UK and Ireland. Aquat Conserv-Mar Freshw Ecosyst 22 (3):337-367. doi:10.1002/aqc.2244

Hilborn R (1985) Fleet dynamics and individual variation - why some people catch more fish than others. Canadian Journal of Fisheries and Aquatic Sciences 42 (1):2-13

Hobday D, Punt AE (2001) Size-structured population modelling and risk assessment of the Victorian southern rock lobster, Jasus edwardsii, fishery. Marine and Freshwater Research 52 (8):1495-1507

Hobday D, Punt AE (2009) How much spatial structure can data for rock lobster off Victoria, Australia support? New Zealand Journal of Marine \& Freshwater Research 43 (1):373-385

Hodrick RJ, Prescott EC (1997) Postwar US business cycles: An empirical investigation. Journal Of Money Credit And Banking 29 (1):1-16

Johnson CR, Banks SC, Barrett NS, Cazassus F, Dunstan PK, Edgar GJ, Frusher SD, Gardner C, Haddon M, Helidoniotis F, Hill KL, Holbrook NJ, Hosie GW, Last PR, Ling SD, Melbourne-Thomas J, Miller K, Pecl GT, Richardson AJ, Ridgway KR, Rintoul SR, Ritz DA, Ross DJ, Sanderson JC, Shepherd SA, Slotvvinski A, Swadling KM, Taw N (2011) Climate change cascades: Shifts in oceanography, species' ranges and subtidal 
marine community dynamics in eastern Tasmania. Journal of Experimental Marine Biology and Ecology 400 (1-2):17-32. doi:10.1016/j.jembe.2011.02.032

Linnane A, Gardner C, Hobday D, Punt A, McGarvey R, Feenstra J, Matthews J, Green B (2010) Evidence of large-scale spatial declines in recruitment patterns of southern rock lobster Jasus edwardsii, across south-eastern Australia. Fish Res 105 (3):163-171. doi:10.1016/j.fishres.2010.04.001

Lyle J (2008) Tasmanian recreational rock lobster and abalone fisheries 2006/07 fishing season. Tasmanian Aquaculture and Fisheries Institute, University of Tasmania, Hobart

McGarvey R, Feenstra JE (2001) Estimating length-transition probabilities as polynomial functions of premoult length. Marine And Freshwater Research 52 (8):1517-1526

Pecl G, Frusher S, Gardner C, Haward M, Hobday A, Jennings S, Nursey-Bray M, Punt A, Revill H, van Putten I (2009) The East Coast Tasmanian Rock Lobster Fishery: Vulnerability to climate change impacts and adaptation response options. Report to the Australian Government Department of Climate Change, Australia. http://www.climatechange.gov.au/publications/coastline/east-coast-rocklobster.aspx [consulted 6/12/2012]

Perry AL, Low PJ, Ellis JR, Reynolds JD (2005) Climate change and distribution shifts in marine fishes. Science 308 (5730):1912-1915. doi:10.1126/science.1111322

Poos JJ, Bogaards JA, Quirijns FJ, Gillis DM, Rijnsdorp AD (2010) Individual quotas, fishing effort allocation, and over-quota discarding in mixed fisheries. ICES Journal of Marine Science 67:323-333

Punt AE, Hobday D, Gerhard J, Troynikov VS, Zi (2006) Modelling growth of rock lobsters, Jasus edwardsii, off Victoria, Australia using models that allow for individual variation in growth parameters. Fish Res 82 (1-3):119-130

Punt AE, Kennedy RB (1997) Population modelling of Tasmanian rock lobster, Jasus edwardsii, resources. Marine and Freshwater Research 48 (8):967980

Punt AE, Kennedy RB, Frusher SD (1997) Estimating the size-transition matrix for Tasmanian rock lobster, Jasus edwardsii. Marine and Freshwater Research 48 (8):981-992

Reeves SA, Marchal P, Mardle S, Pascoe S, Prellezo R, Thébaud O, Travers M (2009) From Fish to Fisheries: The Changing Focus of Management Advice. In: Advances in Fisheries Science. Blackwell Publishing Ltd., pp 135-154. doi:10.1002/9781444302653.ch7

Smith MD (2002) Two econometric approaches for predicting the spatial behavior of renewable resource harvesters. Land Economics 78 (4):522-538

Soulié J-C, Thébaud O (2006) Modeling fleet response in regulated fisheries: An agent-based approach. Math Comp Mod 44 (5-6):553-564

van Putten IE, Kulmala S, Thebaud O, Dowling N, Hamon KG, Hutton T, Pascoe S (2012) Theories and behavioural drivers underlying fleet dynamics models. Fish Fish 13 (2):216-235. doi:10.1111/j.1467-2979.2011.00430.x

Vermard Y, Marchal P, Mahevas S, Thebaud O (2008) A dynamic model of the Bay of Biscay pelagic fleet simulating fishing trip choice: the response to the closure of the European anchovy (Engraulis encrasicolus) fishery in 2005. Canadian Journal of Fisheries and Aquatic Sciences 65 (11):24442453

Ziegler PE, Frusher SD, Johnson CR (2003) Space-time variation in catchability of southern rock lobster Jasus edwardsii in Tasmania explained by environmental, physiological and density-dependent processes. Fish Res $61(1-3): 107-123$ 
Tables

Table 1 Overview of the fleet dynamic models

\begin{tabular}{|c|c|c|c|c|}
\hline Model & Approach & $\begin{array}{l}\text { Seasonal } \\
\text { distribution of } \\
\text { catch }\end{array}$ & $\begin{array}{l}\text { Spatial } \\
\text { distribution of } \\
\text { catch }\end{array}$ & Stochasticity* \\
\hline FD0 & Static model & $\begin{array}{l}\text { Constant } \\
\text { equal to } \\
\text { historical } \\
\text { pattern (1997- } \\
\text { 2006) }\end{array}$ & $\begin{array}{l}\text { Constant equal } \\
\text { to historical } \\
\text { pattern (1997- } \\
2006)\end{array}$ & None \\
\hline FD1 & Linear model & $\begin{array}{l}\text { Constant } \\
\text { equal to } \\
\text { historical } \\
\text { pattern (1997- } \\
2006 \text { ) }\end{array}$ & $\begin{array}{l}\text { Linear } \\
\text { regression of } \\
\text { historical pattern } \\
\text { and local } \\
\text { exploitable } \\
\text { biomass }\end{array}$ & None \\
\hline FD2 & $\begin{array}{l}\text { Agent-based } \\
\text { model of effort } \\
\text { allocation and } \\
\text { quota trading }\end{array}$ & \multicolumn{2}{|c|}{$\begin{array}{l}\text { Catch distribution from spatial and } \\
\text { temporal individual effort } \\
\text { allocation. } \\
\text { Effort allocation based on } \\
\text { expected marginal profit }\end{array}$} & $\begin{array}{lr}\text { Probability } & \text { of } \\
\text { activity } & \text { choice } \\
\text { proportional to } \\
\text { expected marginal } \\
\text { profit }\end{array}$ \\
\hline
\end{tabular}

* Lobster settlement is stochastic, only the stochasticity relevant to the fleet dynamics models is indicated here.

Table 2 Sources of economic data

\begin{tabular}{|l|l|}
\hline Data & Source \\
\hline $\begin{array}{l}\text { Average monthly lobster price } \\
+ \text { price per size and colour }\end{array}$ & $\begin{array}{l}\text { DPIPWE, 1990-2010 } \\
\text { Individual processor, 2009 only }\end{array}$ \\
\hline $\begin{array}{l}\text { Historical monthly fuel prices } \\
\text { Future fuel prices }\end{array}$ & $\begin{array}{l}\text { www.fuelwatch.wa.gov.au/ 2006 - Apr 2010 } \\
\text { Northern Prawn assessment report (Anon } \\
\text { 2010a) }\end{array}$ \\
\hline $\begin{array}{l}\text { Bait, ice and food usage and } \\
\text { price, fuel usage, equipment } \\
\text { cost, crew and skipper wages }\end{array}$ & Gardner and van Putten (2008) \\
\hline $\begin{array}{l}\text { Quota ownership and vessel } \\
\text { characteristics }\end{array}$ & DPIWPE as of 2007 \\
\hline
\end{tabular}


Table 3 Difference in proportion of the catch taken during winter between scenario CC-HistS-IncP and the other lobster price scenarios CC-NewS-IncP, CC-NewS-ConP and CC-HistS-ConP in 2007 and 2016 for the 50 simulation runs.

\begin{tabular}{|l|l|l|}
\hline Model tested $\left(\mathrm{H}_{0}\right)$ & 2007 coeff (Pvalue) & 2016 coeff (Pvalue) \\
\hline HistS-IncP-NewS-IncP $=0$ & $-0.04(0.18)$ & $4.97(<0.001)$ \\
\hline HistS-IncP-NewS-ConP $=0$ & $0.03(0.41)$ & $6.87(<0.001)$ \\
\hline HistS-IncP-HistS-ConP $=0$ & $0.63(<0.001)$ & $6.69(<0.001)$ \\
\hline
\end{tabular}

${ }^{i}$ At time of writing AU\$1 = US\$1.05 = EUR0.80 (source: $\underline{\text { http://coinmill.com) }}$

\section{Figures}

Fig. 1 Map of Tasmania and the stock assessment areas for the rock lobster fishery

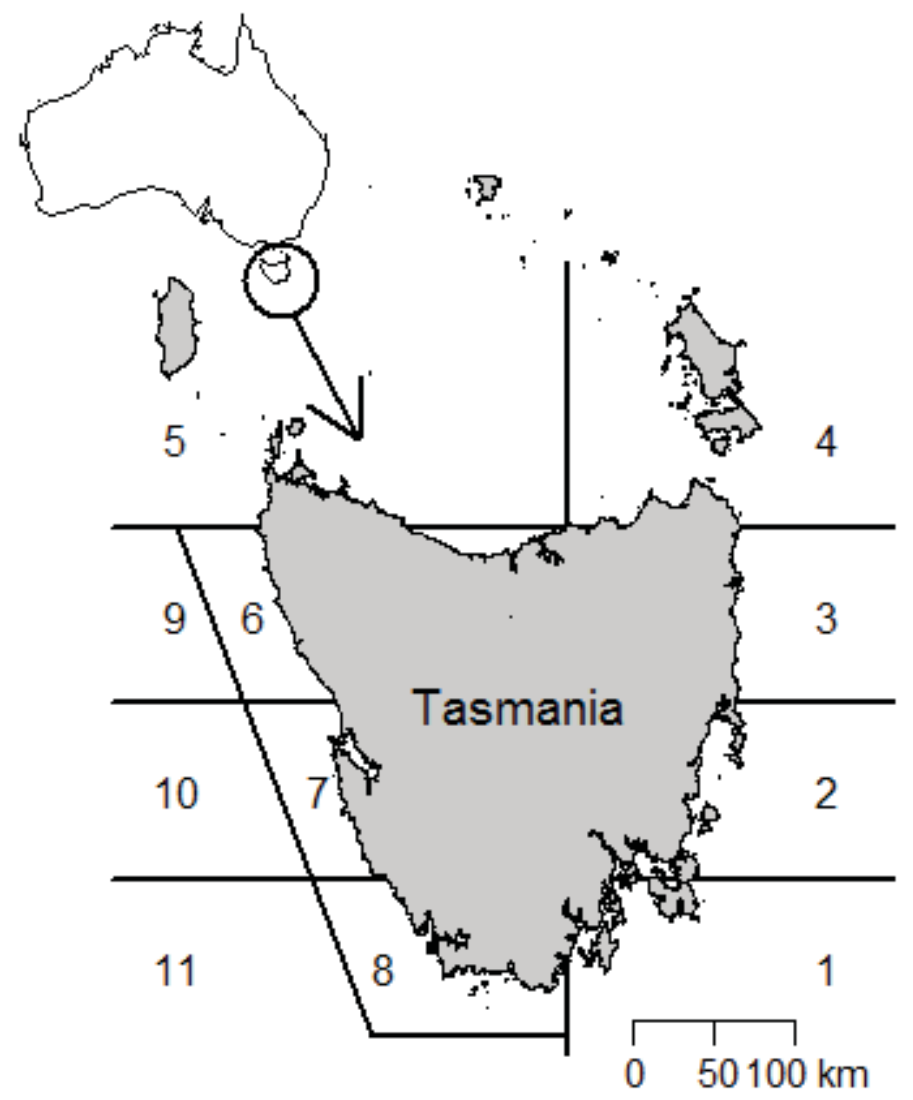


Fig. 2 Time-trajectories of average exploitable biomass on 1 January of each year by area for the three fleet dynamics models with (black lines) or without (grey lines) climate change for 2007-2016. The black horizontal lines represent the lowest exploitable biomass in each area since 1998. The areas are positioned as in Fig 1, Northern areas on top and western areas on the left

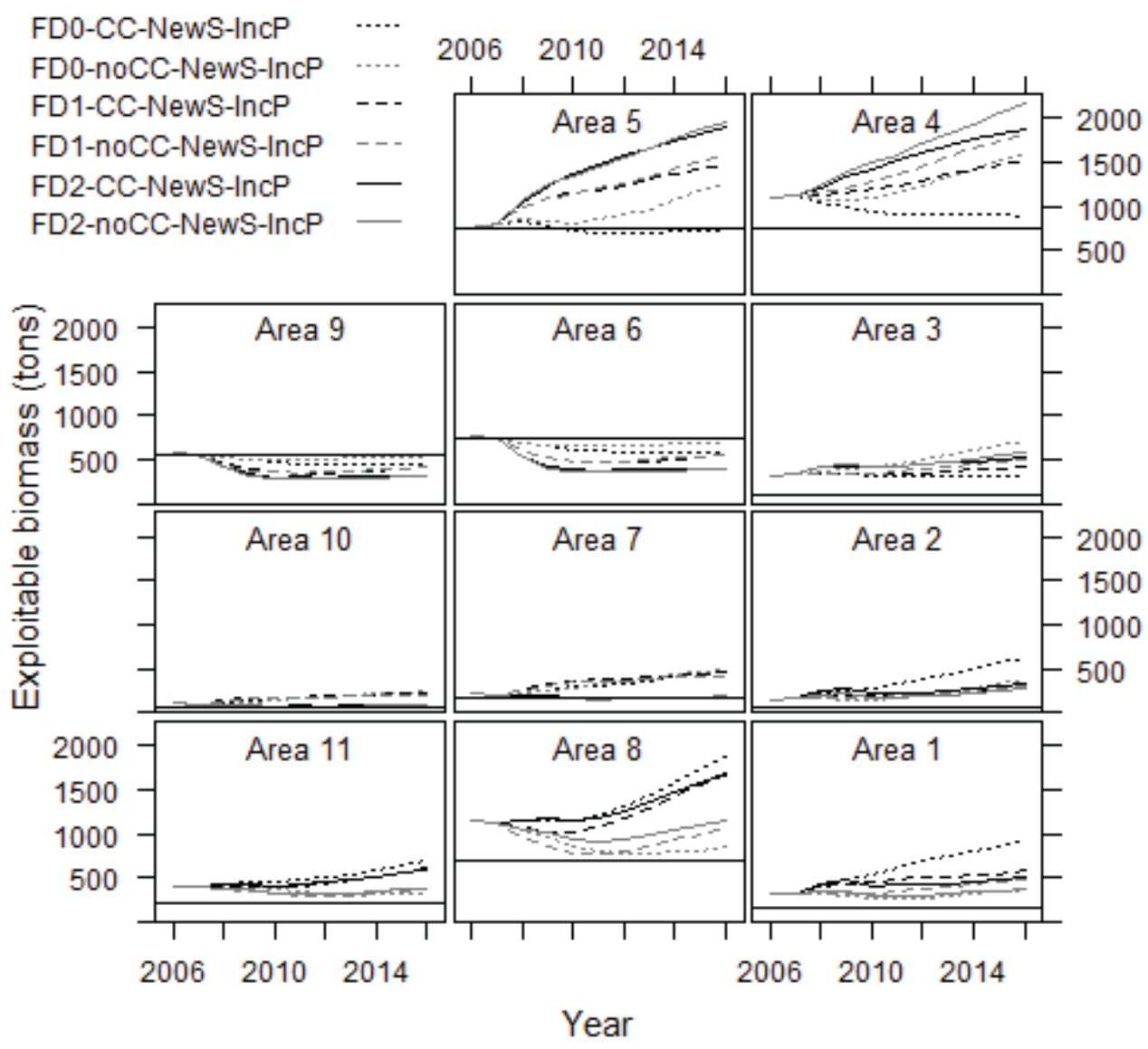


Fig. 3 Time-trajectories of average simulated catch ( $\mathrm{t}$ ) by year and area for the three fleet dynamics models with (black lines) or without (grey lines) climate change for the period 2007-2016. Black dots represent the actual observations The areas are positioned as in Fig. 2

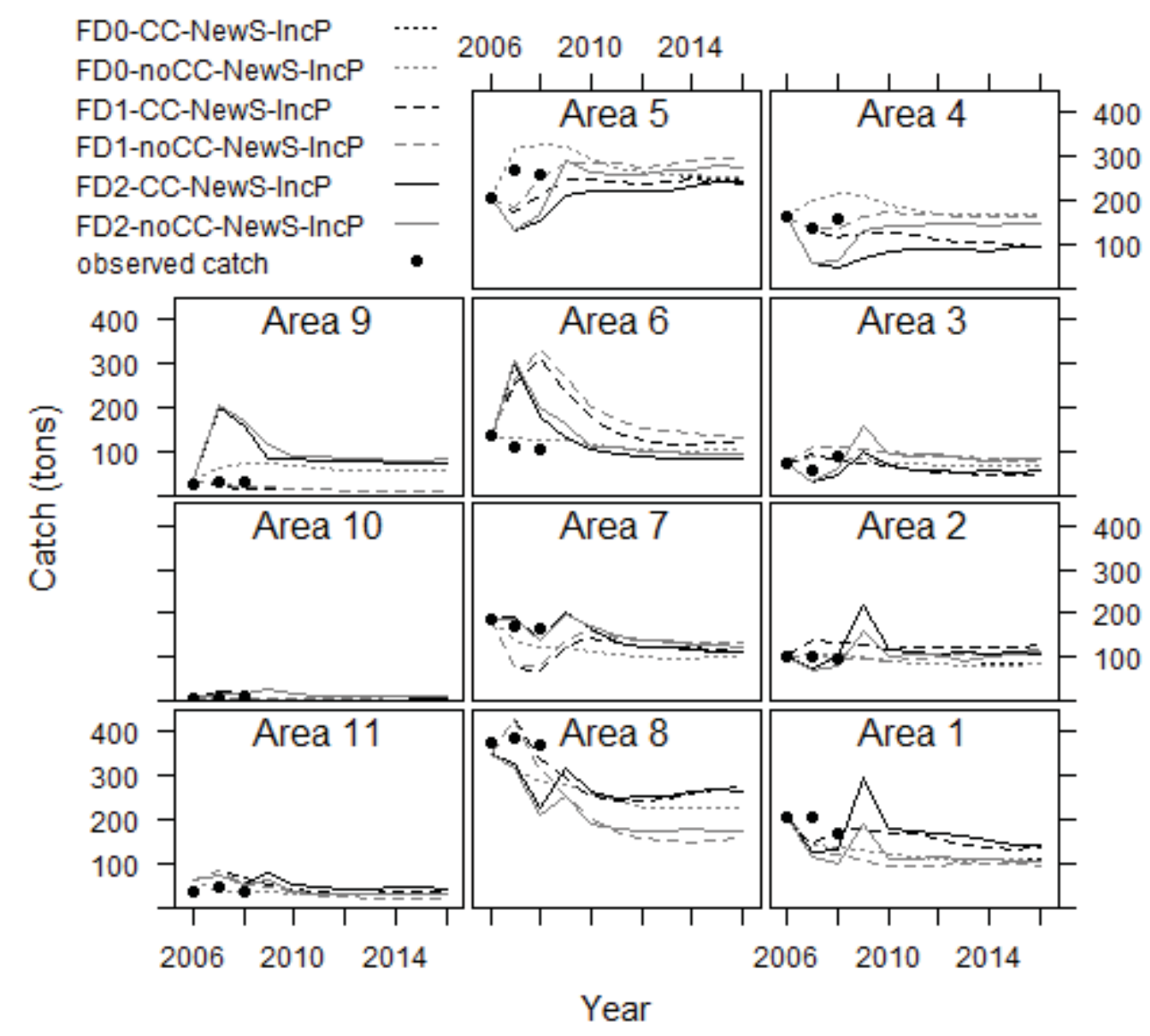


Fig. 4 Time-trajectories of average simulated effort (thousands of trap lifts) by year and area for the three fleet dynamics models with (black lines) or without (grey lines) climate change for the period 2007-2016. Black dots represent the actual observations. The $y$-axis scale is different for area 5 ( 0 to 1500) than for the other areas (0 to 500). The areas are positioned as in Fig. 2
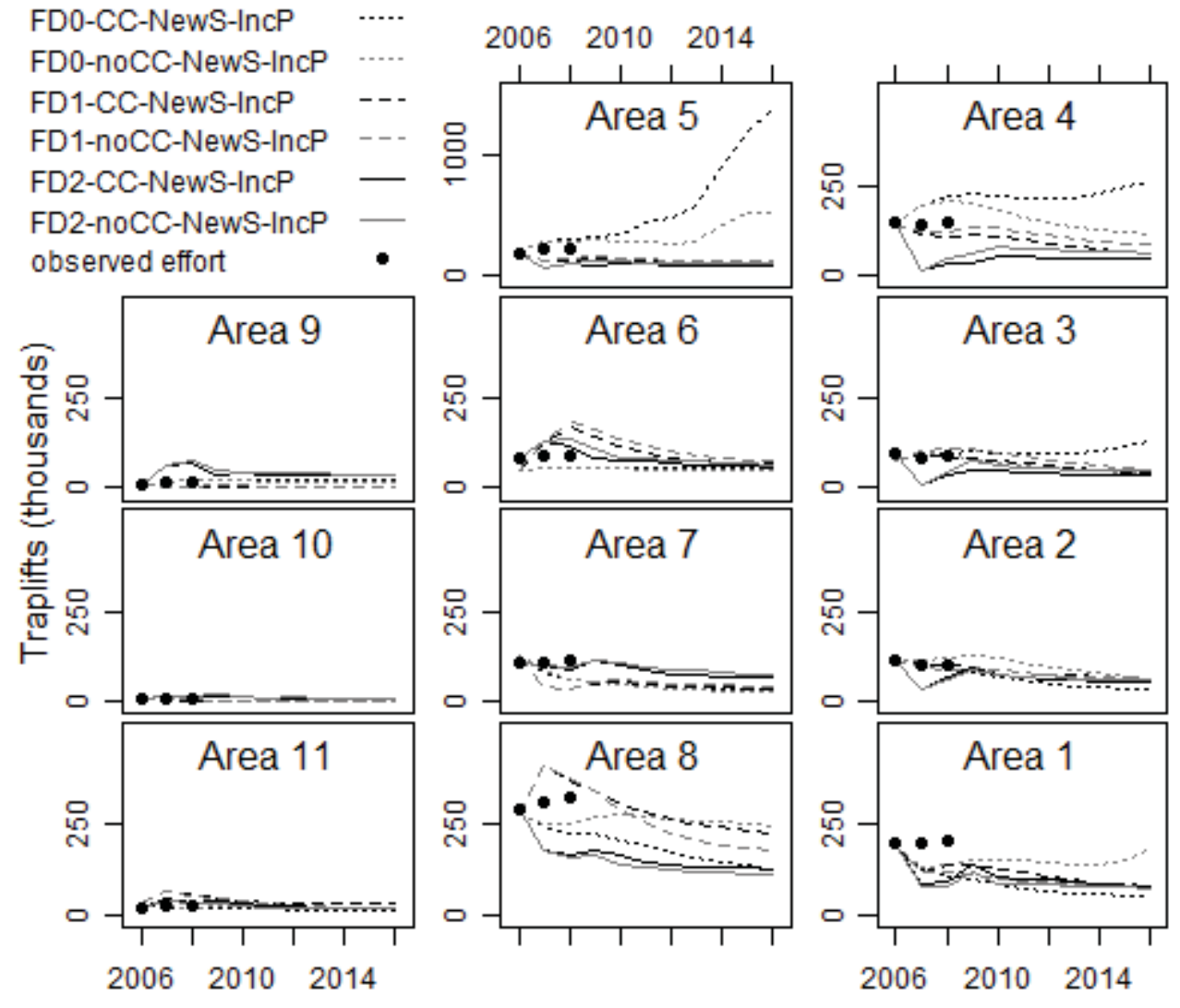

Year 
Fig. 5 Relative exploitable biomass by area: a) with (scenario CC-News-IncP) and b) without (scenario noCC-News-IncP) climate change for the three effort dynamics models. Biomass by area and statewide ("all") in 2016 is expressed relative to the lowest observed exploitable biomass between 1998 and 2007 . Error bars represent the dispersion of model outputs. The dashed horizontal line represents the reference point (relative exploitable biomass $=1$ )

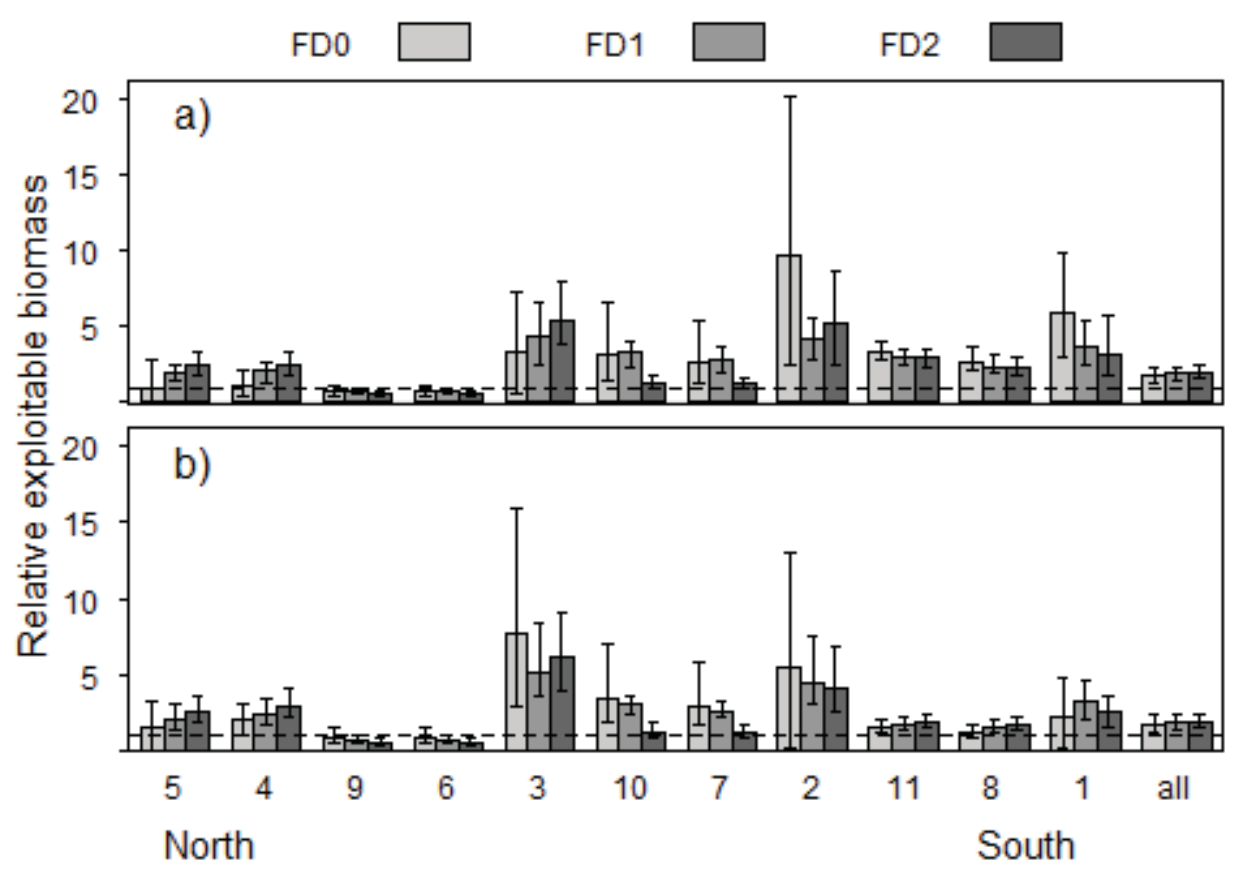


Fig. 6 Average of the economic indicators a) landings value, b) fishing costs and c) profit in 2016. Economic indicators are calculated for all models (grey shades) and scenarios (x-axis). Vertical bars represent the range of model outputs

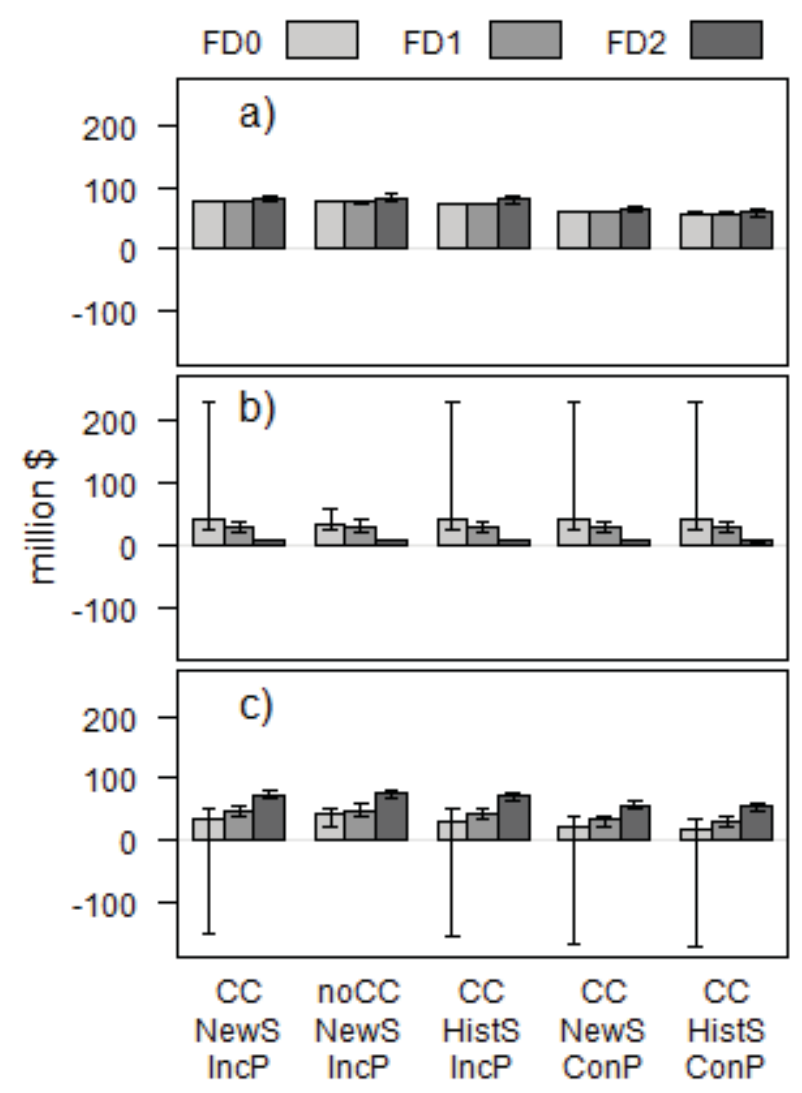

Fig. 7 Average number of vessels in the fishery by effort dynamics model in 2016 . Number of active vessels in the fishery compiled for the FD2 model and all scenarios (X-axis). The number of vessels is assumed constant the 2007 level for models FD0 and FD1. Vertical bars represent between-run variation in model outputs

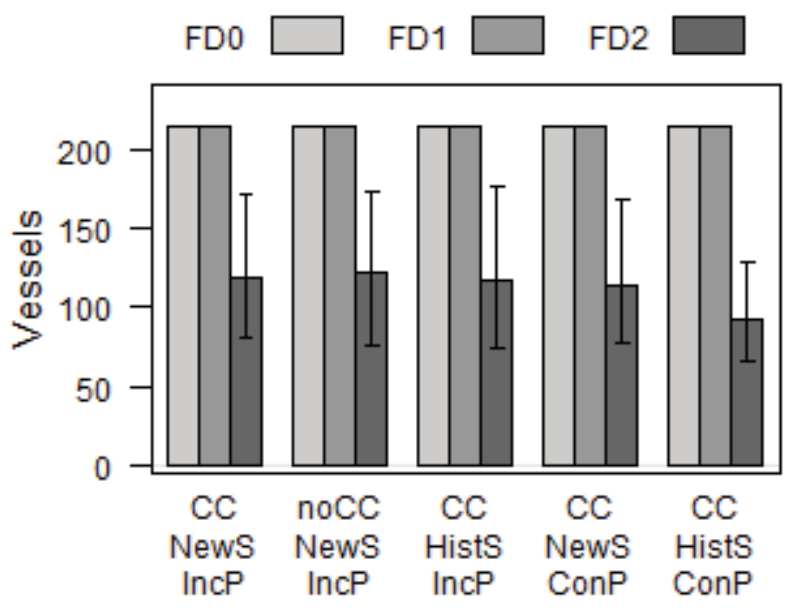

